\title{
PELAKSANAAN BIMBINGAN ANAK TERLANTAR GUNA MENINGKATKAN LIFE SKILLS DI SASANA PELAYANAN SOSIAL ANAK "KUMUDA PUTRA PUTRI" MAGELANG
}

\section{IMPLEMENTATION OF ADDITIONAL CHILDREN TO IMPROVE LIFE SKILLS IN SOSIAL SERVICE CHILDREN "KUMUDA PUTRA PUTRI" MAGELANG}

\author{
Oleh: Hanif Taufiqul Hakim, Universitas Negeri Yogyakarta \\ Haniftaufiq14@gmail.com
}

\begin{abstract}
Abstrak
Penelitian ini bertujuan untuk mendeskripsikan: (1) Pelaksanaan bimbingan anak terlantar guna meningkatkan life skills di Sasana Pelayanan Sosial Anak "Kumuda Putra Putri” Magelang. (2) Faktor pendukung dan penghambat pelaksanaan bimbingan anak terlantar guna meningkatkat life skills di Sasana Pelayanan Sosial Anak "Kumuda Putra Putri” Magelang. Penelitian kualitatif dengan metode deskriptif. Hasil penelitian yaitu (1). Pelaksanaan bimbingan anak terlantar guna meningkatkan life skills di SPSA meliputi 3(tiga) macam bimbingan yaitu : (a) Bimbingan mental spiritual; (b) Bimbingan mengaji; dan (c) Bimbingan karakter (2) Faktor Pendukung dalam pelaksanaan bimbingan anak terlantar guna meningkatkan life skills di SPSA yaitu adanya kerjasama pendamping dengan pihak lura/lembaga, adanya dukungan dari Dinas Sosial Provinsi Jawa Tengah, tersedianya sarana prasarana pelaksanaan bimbingan. Faktor penghambat dalam pelaksanaan bimbingan anak terlantar guna meningkatkan life skills di SPSA yaitu adanya latar belakang yang berbeda antara anak satu dengan yang lainnya, adanya anak yang bercanda dengan teman sekitar saat pelaksanaan bimbingan dan keterbatasan waktu yang dimiliki anak asuh dalam mengikuti keseluruhan pembinaan.
\end{abstract}

Kata kunci: bimbingan, anak terlantar, life skills

Abstract

This study aims to describe: (1) Implementation of guidance of abandoned children to improve life skills at Sasana Child Social Service "Kumuda Putra Putri" Magelang. (2) Supporting factors and inhibiting the implementation of guidance of abandoned children in order to increase the life skills in Sasana Child Social Service "Kumuda Putra Putri" Magelang. Qualitative research with descriptive method. The result of this research are (1). Implementation of guidance of abandoned children to improve life skills in SPSA includes 3 (three) kinds of guidance that is: (a) spiritual mental guidance; (B) Tutoring guidance; And (c) Character guidance (2) Supporting factors in the implementation of the guidance of abandoned children to improve life skills in SPSA namely the cooperation with the party out of / institution, the support of the Central Java Provincial Social Service, the availability of infrastructure facilities implementation of guidance. Inhibiting factors in the implementation of guidance of abandoned children to improve life skills in SPSA is the existence of different backgrounds between children with one another, the existence of children who joked with friends around during the implementation of guidance and limited time of foster children in following the overall coaching.

Keywords: Guidance, abandoned children, life skills

\section{PENDAHULUAN}

Kota Magelang memiliki penduduk dengan jumlah yang relatif banyak yakni 120,373 jiwa (BPS, 2014). Namun dari jumlah penduduk secara keseluruhan terdapat penduduk yang miskin sebesar 980 ribu jiwa (BPS, 2014). Secara umum penduduk miskin mengalami kesulitan 


\section{Diklus: Jurnal Pendidikan Luar Sekolah, 1(2), September 2017 - 210 Hanif Taufiqul Hakim}

dalam mengakses layanan kesehatan, pendidikan dan dunia kerja atau kesempatan kerja.

Pemerataan kesejahteraan sosial menjadi permasalahan kompleks yang menunjukan bahwa adanya hak-hak masyarakat yang belum terpenuhi, sehingga menyebabkan masyarakat kesulitan dalam menjalankan fungsi sosialnya. Menurut Undang-Undang No. 11 Tahun 2009 Tentang Kesejahteraan Sosial menyebutkan bahwa "Kesejahteraan sosial adalah kondisi terpenuhinya kebutuhan material, spiritual, dan sosial warga negara agar dapat hidup layak dan mampu mengembangkan diri, sehingga dapat melaksanakan fungsi sosialnya". Berdasarkan Undang-Undang tersebut pemerintah sudah seharusnya melaksanakan penyelenggaraan kesejahteraan sosial bagi masyarakat. Penyelengaraan kesejahteraan sosial meliputi rehabilitasi sosial, jaminan sosial, pemberdayaan sosial, dan perlindungan sosial. Sesuai yang tercantum dalam Undang-Undang No. 11 Tahun 2009 Pasal 9 Ayat 1 menyatakan bahwa "Jaminan sosial yang dimaksud adalah fakir miskin, anak yatim piatu terlantar, lanjut usia terlantar, penyandang cacat fisik, cacat mental, cacat fisik dan mental, eks penderita penyakit kronis yang mengalami masalah ketidakmampuan sosialekonomi agar kebutuhan dasarnya terpenuhi”. Penanganan masalah kesejahteraan sosial bagi anak terlantar merupakan kewajiban pemerintah sesuai yang tercantum dalam pasal 34 UUD 1945, bahwa "fakir miskin dan anak terlantar dipelihara oleh Negara".

Secara yuridis anak terlantar dan fakir miskin dipelihara oleh negara, hal ini tidak berarti sebagai masyarakat lepas tanggung jawab terhadap anak terlantar dan fakir miskin atau penyandang masalah kesejahteraan sosial (PMKS). Menurut Badan Pusat Statistik jumlah anak terlantar di Kabupaten dan Kota Magelang dari 1.921 di tahun 2012 lalu meningkat menjadi 7.705 di tahun 2013. Banyak anak mengalami keterlantaran baik secara jasmani dan rohani yang menyebabkan kebutuhan sosialnya tidak terpenuhi. Salah satu penyebab keterlantaran adalah krisis ekonomi yang disebabkan oleh bencana alam yang terjadi diberbagai tempat dan menyebabkan orang tua kehilangan pekerjaannya dan anak-anak kehilangan orang tua dan keluarganya yang menyebabkan menjadi terlantar. Sebab lain yang menjadikan anak terlantar adalah kurangnya perhatian dari orang tuanya, anak lahir di luar nikah, maupun anak yang berasal dari keluarga broken home. Bagi keluarga yang mengalami masalah ekonomi maupun keadaan keluarga yang salah satu atau kedua orang tuanya telah meninggal dunia, pengadaan panti rehabilitasi sosial yang diadakan pemerintah sangat menguntungkan tidak dipungut biaya dan diharapkan mempunyai manfaat bagi kehidupan anak terlantar. Upaya yang dilakukan oleh Pemerintah dalam mensejahterakan kehidupan anak terlantar adalah untuk memenuhi kebutuhan anak terlantar melalui kegiatan bimbingan. Hal tersebut sesuai pendapat Crow dan Crow, dalam Prayitno dan Anti (1999: 94) bahwa, "Bimbingan adalah bantuan yang diberikan oleh seseorang, baik laki-laki maupun perempuan yang memiliki kepribadian yang memadai dan terlatih dengan baik kepada individu-individu setiap usia untuk membantunya mengatur kegiatan hidupnya sendiri, membuat 


\section{Diklus: Jurnal Pendidikan Luar Sekolah, 1(2), September 2017 - 211 \\ Hanif Taufiqul Hakim}

keputusan sendiri dan menanggung bebannya sendiri".

Agar anak-anak kurang mampu dan terlantar tetap memiliki bekal ilmu pengetahuan atau pun skills meski putus sekolah, pemerintah tidak sedikit mengadakan program untuk mendapatkan penghidupan yang layak bagi mereka. Agar mereka dapat lebih percaya diri, mandiri serta tidak ketergantungan dengan orang lain.

\section{METODE PENELITIAN}

\section{Jenis Penelitian}

Penelitian ini menggunakan pendekatan kualitatif dan metode penelitian yang digunakan adalah metode penelitian deskriptif kualitatif. penelitian kualitatif merupakan penelitian yang memahami dan mendalami suatu fenomena atau kondisi di masyarakat yang terjadi secara alami pada subyek penelitian yang selanjutkan dideskripsikan dalam bentuk kata-kata dan bahasa. Penggunaan pendekatan kualitatif deskriptif karena dalam penelitian ini menyajikan, melukiskan atau menggambarkan data secara deskriptif tentang pelaksanaan bimbingan anak terantar guna meningkatkan life skills di Sasana Pelayanan Soial Anak "Kumuda Putra Putri” Magelang.

\section{Waktu dan Tempat Penelitian}

Lokasi penelitian di Sasana Pelayanan Sosial Anak "Kumuda Putra Putri" Magelang yang beralamat di J1. Alibasah Senthot Prawirodirjo No. 940 Magelang Jawa Tengah.

\section{Subyek Penelitian}

Pengambilan data atau subyek dalam penelitian ini menggunakan teknik purposive dengan cara melakukan penentuan sumber data dengan memilih orang yang akan diwawancarai menggunakan pertimbangan tertentu (Sugiyono, 2012: 300). Key informan dalam penelitian ini adalah dipilih dengan pertimbangan memiliki cukup informasi dan mengetahui tentang kegiatan atau program pelayanan sosial bagi lansia di Dusun Bulak, baik terlibat secara langsung maupun terlibat secara tidak langsung. Subyek penelitian yang menjadi key informan atau yang memiliki cukup informasi tentang fokus penelitian adalah pembimbing dalam peningkatan life sills.

Selain key informan, subyek penelitian yang menjadi informan dalam penelitian ini adalah instruktur bimbingan di Sasana Pelayanan Sosial Anak “Kumuda Putra Putri” Magelang

\section{Data, Intrumen, dan Teknik Pengumpulan} Data

Teknik pengumpulan data dilakukan dengan observasi partisipasi, wawancara mendalam, dan dokumentasi terhadap kelengkapan arsip atau dokumen kelompok.

\section{Teknik Analisis Data}

Analisis data menggunakan teknik analisis model interaktif yang terdiri dari reduksi data, penyajian data, dan penarikan kesimpulan.

\section{Reduksi Data}




\section{Diklus: Jurnal Pendidikan Luar Sekolah, 1(2), September 2017 - 212 Hanif Taufiqul Hakim}

Reduksi data didalam penelitian ini dimaksudkan dengan merangkum data, memilih hal-hal pokok, disusun secara sistematik sehingga memberikan gambaran secara jelas terkait dengan hasil pengamatan. Kemudian peneliti membuat ringkasan terhadap data yang telah diperoleh dan dikumpulkan agar peneliti mudah dalam mengendalikan data sesuai dengan kebutuhan penelitian.

\section{Display Data}

Data yang diperoleh di lapangan berupa uraian deskriptif kemudian disajikan secara sederhana untuk memudahkan peneliti memahami hasil penelitian yang telah diperoleh. Sehingga peneliti dapat mengetahui tindakan apa yang akan dilakukan selanjutnya.

\section{Penarikan Kesimpulan}

Pada tahap ketiga ini merupakan tahapan dimana peneliti harus memaknai data yang terkumpul kemudian dibuat dalam bentuk pernyataan singkat dan mudah dipahami dengan mengacu pada masalah yang diteliti. Data tersebut dibandingkan dan dihubungkan dengan yang lainnya, sehingga mudah ditarik kesimpulan sebagai jawaban dari setiap permasalahan yang ada.

\section{Keabsahan Data}

Dalam penelitian ini, peneliti menggunakan triangulasi sumber dan triangulasi teknik. Triangulasi sumber dilakukan dengan cara memeriksa data yang didapat dari beberapa sumber. Data dari beberapa sumber tersebut dideskripsikan dan dikategorisasikan, mana pandangan yang sama, yang berbeda, dan mana spesifik dari beberapa sumber data itu. Sedangkan, triangulasi teknik digunakan untuk menguji kredibiltas data yang dilakukan dengan cara mengecek data kepada sumber yang sama dengan teknik yang berbeda.

\section{HASIL PENELITIAN DAN PEMBAHASAN}

Kehidupan Anak Terlantar/Penerima

\section{Manfaat di Sasana Pelayanan Sosial Anak}

“Kumuda Putra Putri” Magelang.

Sasana Pelayanan Sosial Anak "Kumuda Putra-Putri” Magelang merupakan salah satu unit pelaksana teknis Dinas Sosial Provinsi Jawa Tengah yang melaksanakan kegiatan operasional pelayanan sosial untuk mempersiapkan para anak terlantar yang meliputi anak yatim, piatu, yatim piatu terlantar, anak korban kekerasan dan anak keluarga tidak mampu agar dapat hidup secara mandiri dan menjalankan fungsi sosialnya secara wajar.

Kehidupan anak terlantar yang tinggal di dalam panti tidak jauh berbeda dengan kehidupan anak-anak di lingkungan masyarakat pada umumnya. Mereka juga melakukan kegiatan sehari-hari seperti kegiatan sekolah dan mengisi waktu luang. Kondisi latar belakang ekonomi dan sosial mereka yang membuat anak terlantar mempunyai keinginan untuk hidup lebih mandiri. Hal tersebut dapat diwujudkan dengankegiatankegiatan yang mendasarkan pada pengembangan kemampuan anak terlantar agar menjadi mandiri, bermanfaat bagi diri sendiri dan orang lain. Keinginan mandiri yang dimaksud adalah kemandirian anak dalam menjalani kehidupan 


\section{Diklus: Jurnal Pendidikan Luar Sekolah, 1(2), September 2017 - 213 Hanif Taufiqul Hakim}

sehari-hari di panti dan kehidupan setelah keluar dari panti.

\section{Bentuk Bimbingan}

Di Sasana Pelayanan Sosial Anak "Kumuda Putra Putri” Magelang terdapat empat macam bimbingan yaitu bimbingan mental spiritual, bimbingan mengaji, bimbingan karakter dan bimbingan keterampilan pendidikan. Bimbingan Mental Spiritual meliputi pendampingan terhadap semua anak asuh baik secara kelompok dan individu. Hasil pengamatan di lapangan menunjukkan bahwa kegiatan bimbingan yang dilakukan pendamping untuk meningkatkan life skills khususnya dalam peningkatan kesadaran spiritual dan kecakapan komunikasi. Kegiatan diisi dengan ceramah oleh Kementrian Agama yang dilakukan di aula/moshula dan anak asuh duduk melingkar dalam kegiatan. Sebelum kegiatan dilaksanakan anak-anak terlebih dahulu berdoa agar kegiatan berjalan dengan lancar. Kegiatan ceramah mengambil materi keagamaan yang sederhana meliputi kegiatan sehari-hari anak seperti cara bergaul dengan teman, bersikap dan lain sebagainya. Selain ceramah pembelajaran juga melalui praktek langsung seperti tatacara wudhu yang benar. Metode penyampaian materi dilakukan dengan ceramah, diskusi, tanya jawab dan praktek. Media pembelajaran yang digunakan adalah leaflet. Hasil pengamatan menunjukkan bahwa pada kegiatan ini dapat memberikan dan meningkatkan life skills anak asuh karena memberikan anak dapat menjadi pribadi yang lebih dekat dengan Tuhan Yang Maha Esa serta meningkatkan life skills anak dalam aspek keagamaan.

Bimbingan membaca Al Qur'an meliputi kegiatan membaca Al Qur'an dengan metode Qiroati. Bimbingan mengaji ini pihak Sasana Pelayanan Sosial Anak "Kumuda Putra Putri”" Magelang bekerja sama dengan Yayasan Manajeman Silaturahim yang dilaksanakan setiap hari Selasa pukul 15.30-17.00 WIB yang dilaksanakan untuk putra di Mushola dan untuk putri di ruang gedung serba guna. Setiap kegiatan selalu ada presensi guna memantau kehadiran dan keaktifan anak dalam mengikuti bimbingan. Dalam bimbingan mengaji setiap anak diberikan kartu prestasi Qiroati guna mengetahui perkembangan anak.

Bimbingan karakter yang diberikan oleh Sasana Pelayanan Sosial Anak "Kumuda Putra Putri” Magelang meliputi kegiatan baris-berbaris, olahraga dan kegiatan kedisiplinan melalui kegiatan apel. Pelaksanaan bimbingan karakter dilaksanakan setiap hari Rabu pukul 15.30-17.00 WIB yang dilaksanakan di lapangan Sasana Pelayanan Sosial Anak "Kumuda Putra Putri" Magelang atau jika cuaca hujan dilaksanakan di Aula. Pelaksanaan kegiatan PBB (baris-berbaris) oleh Koramil. Sebelum kegiatan dimulai, terlebih dahulu anak-anak berdoa demi kelancaran bimbingan. Kemudian setelah berdoa, pembimbing kegiatan menanyakan kabar kepada anak asuh untuk mengawali kegiatan. Kegiatan selanjutnya adalah senam dan kegiatan barisberbaris.

Kegiatan senam dilakukan dengan gerakangerakan sederhana seperti menggerakkan 


\section{Diklus: Jurnal Pendidikan Luar Sekolah, 1(2), September 2017 - 214 Hanif Taufiqul Hakim}

anggota bagian tubuh (tangan, kepala, pundak, dan kaki) Kegiatan senam ini tanpa iringan musik, anak menghitung sampai delapan kali hitungan dan gerakan berganti dari gerakan kepala, pundak, tangan dan kaki. Kegiatan barisberbaris/PBB, anak melakukan perintah yang dikatakan pembimbing/instuktur kegiatan seperti hadap kanan/kiri, balik kanan, serong kanan/kiri, jalan ditempat, dan hormat.

Pembimbing/instruktur kegiatan akan memperbaiki sikap badan, tangan dan kaki jika anak masih melakukan kesalahan dalam barisberbaris. Metode pembelajaran yang digunakan ceramah, diskusi, tanya jawab dan praktek. Dalam pelaksanaan bimbingan fisik tidak memerlukan sarana prasarana maupun media pembelajaran secara khusus karena kegiatan banyak dilakukan di lapangan. Kegiatan fisik dilakukan bukan hanya untuk memperkuat daya tahan tubuh anak saja, melainkan untuk meningkatkan kedisiplinan anak baik dalam kegiatan sekolahnya maupun kegiatan dalam panti.

Pembimbing/instruktur dari Koramil juga memberikan materi tentang kedisiplinan melalui penataan baju yang ada dilemari dan penataan sepatu di rak sepatu. Selain itu, pembimbing juga menanamkan disiplin dalam kegiatan makan dan belajar. Disiplin dalam makan seperti menata meja dan kursi setelah makan, mencuci piring dan mengembalikan ketempatnya seperti semula. Pada kegiatan belajar, pembimbing memberikan arahan dan pengertian agar anak pandai mengatur waktu antara belajar dan kegiatan di dalam sasana.
Sebelum melakukan bimbingan karakter anak asuh melakukan apel terlebih dahulu dan di presensi untuk mengetahui kehadiran anak jika ada anak yang tidak hadir maka segera diberitahukan kepada pembimbing beserta alasan ketidakhadirannya.

Pelaksanaan bimbingan pendidikan meliputi pendidikan formal baik SD, SLTP, SLTA/SMK dan kegiatan sekolah anak dimulai pukul 07.00-15.00 WIB. Selain kegiatan sekolah, anak juga melakukan kegiatan belajar bersama untuk mengulang dan memperdalam materi yang sudah diberikan anak di sekolah. Anak asuh biasanya meminta bantuan untuk mengerjakan $\mathrm{PR} /$ tugas yang diberikan oleh sekolah, biasanya mengerjakan soal-soal bidang studi yang akan diujikan bagi anak-anak yang akan mengikuti ujian nasional atau tugas lainnya. Anak-anak melakukan belajar malam bersama pada pukul 20.00-21.00 WIB bertempat di Aula.

Ada ruangan musik dan menjahit namun pada tahun ini tidak dilaksanakan pelatihan karena dana dari pemerintah di pangkas. Sehingga anak tetap bisa menggunakan fasilitas itu namun tidak ada pendamping sehingga anak tetap bisa mengasah keterampilan dan bakatnya di ruangan tersebut.

Setelah semua program terlaksana, selanjutnya yaitu tahap evaluasi program. Evaluasi dilaksanakan guna mengetahui apakah sebuah program yang telah dilaksanakan sesuai yang diharapkan atau dengan perencanaan atau belum. Eavaluasi pada pendampingan life skills/kecakapan hidup ini dilakukan pada saat kegiatan bimbingan berlangsung. 


\section{Diklus: Jurnal Pendidikan Luar Sekolah, 1(2), September 2017 - 215 \\ Hanif Taufiqul Hakim}

\section{Peran Pembimbing}

Menurut Depsos (2007:4), pendampingan adalah suatu proses relasi sosial antara pendamping dengan korban dalam bentuk pemberian kemudahan (fasilitas) untuk mengidentifikasi kebutuhan dan memecahkan masalah serta mendorong tumbuhnya inisiatif dalam proses pengambilan keputusan, sehingga kemandirian korban secara berkelanjutan dapat diwujudkan. Pendamping yang dimaksud adalah pekerja sosial yang dengan keahliannya atau pekerjaannya mendahulukan tugas-tugas pendampingan di mana yang bersangkutan bekerja sesuai dengan prinsip, metode dan pekerjaan sosial (Depsos, 2007:4).

Pembela (Advocator) Pendamping melakukan pembelaan pada korban yang mendapatkan perlakuan tidak adil. Pendamping sebagai pembela pada dasarnya berfokus pada korban, mendampingi korban dalam proses hukum, mengembangkan peranan, tugas dan sistem yang berlaku. Pendamping berperan sebagai penghubung klien dengan sistem sumber yang ada baik formal maupun informal, dalam rangka merujuk dan sebagai tindak lanjut dari pelayanan yang diberikan. Pendamping berperan dalam mengidentifikasi permasalahan korban kebutuhan dan menjajagi langkah-langkah menghadapi permasalahannya. Pendamping berperan dalam melakukan penjangkauan kepada kelompokkelompok yang rentan terhadap kekerasan dan korban tindak kekerasan yang membutuhkan layanan perlindungan awal dan pemulihan psikososial. Pendamping berperan dalam memberikan rangsangan dan dorongan semangat kepada klien untuk dapat bersikap positif, pola pikir dan mengembangkan potensi sebagai upaya pemulihan.

\section{Faktor Pendukung Pelaksanaan Bimbingan}

Adapun faktor-faktor yang mempengaruhi dalam pelaksanaan bimbingan antara lain: Adanya kerjasama pendamping dan pihak luar/lembaga terkait dalam pelaksanaan pembinaan, Adanya dukungan dari Dinas Sosial Provinsi Jawa Tengah., Tersedianya sarana prasarana pelaksanaan pembinaan

\section{Faktor PenghambatPelaksanaan Bimbingan}

Adapun faktor penghambat pelaksanaan bimbingan meliputi: Adanya latar belakang yang berbeda antara anak satau dengan yang lainnya sehingga ada penanganan sendiri-sendiri. Adanya anak yang bercanda dengan teman disekitarnya ketika kegiatan berlangsung. Keterbatasan waktu yang dimiliki anak dalam mengikuti keseluruhan pembinaan karena pulang sekolah sudah sore, kerja kelompok, ikut ekstrakulikuler di sekolah, les di sekolah maupun di luar sekolah, alasan anak pulang kerumah, faktor lupa maupun anak yang tertidur.

\section{SIMPULAN DAN SARAN}

\section{Simpulan}

Berdasarkan hasil penelitian dan pembahasan tentang pelaksanaan bimbingan anak terlantar guna meningkatkan life skills di Sasana 
Pelayanan Sosial Anak "Kumuda Putra Putri" Magelang dapat disimpulkan bahwa:

a. Pelaksanaan bimbingan anak terlantar guna meningkatkan life skills di Sasana Pelayanan Sosial Anak "Kumuda Putra Putri” Magelang meliputi penentuan materi, metode dan media pembelajaran kemudian adanya evaluasi. Penyampaian materi dengan bahasa yang mudah dipahami oleh anak asuh dan diselingi dengan contoh kehidupan sehari-hari sehingga memudahkan anak untuk memahami materi yang disampaikan. Metode yang digunakan dalam penyampaian materi adalah metode ceramah, diskusi, tanya jawab dan praktek. Media pembelajaran yang digunakan seperti modul dan lembaran materi/leaflet. Sikap pembimbing yang akrab, ramah, tegas dan humoris membuat suasana belajar menjadi lebih menyenangkan dan anak tidak merasa bosan dengan kegiatan yang ada di Sasana. Bentuk bimbingan guna meningkatkan life skills antara lain: bimbingan mental spiritual, bimbingan mengaji, bimbingan karakter dan bimbingan pendidikan. Pelaksanaan bimbingan didasarkan pada metode pekerjaan sosial menggunakan metode bimbingan perseoranga dan kelompok.

b. Peran pendamping/pembimbing dalam meningkatkan life skills (kecakapan hidup) adalah berperan sebagai pendidik (educator) penghubung (mediator) pemampu (enabler) perantara (broker) fasilitator (fasilitator). Life skills yang ada di Sasana Pelayanan Sosial Anak "Kumuda Putra Putri” Magelang mulai dari kesadaran spiritual kedasaran akan potensi kecakapan sosial, kecakapan komunikasi dan kecakapan mengkolaborasikan.

c. Faktor pendukung bimbingan dalam meningkatkan life skills adalah a) adanya kerjasama yang baik antara pihak sasana dan pihak luar lembaga terkait dalam pelaksanaan bimbingan, b) adanya dukungan dari pihak Dinas Sosial Provinsi Jawa Tengah, c) tersedianya sarana prasarana pelaksanaan bimbingan. Faktor penghambat bimbingan guna meningkatkan life skills adalah a) keterbatasan waktu yang dimiliki oleh anak menyebabkan anak tidak mengikuti kegiatan bimbingan, b) adanya anak asuh yang masih bercanda dengan temannya saat pelaksanaan bimbingan, c) masih ada anak yang kurang disiplin dalam mengikuti kegiatan bimbingan di sasana.

\section{Saran}

Berdasarkan hasil penelitisn dalam pelaksanaan bimbingan anak terlantar guna meningkatkan life skills di Sasana Pelayanan Sosial Anak "Kumuda Putra Putri" Magelang, maka dapat dikemukakan beberapa saran sebagai berikut:

a. Pelaksanaan bimbingan guna meningkatkan life skills yang dilakukan di Sasana Pelayanan Sosial Anak "Kumuda Putra Putri” Magelang sebagai upaya peningkatan kecakapan hidup dalam upaya pelayanan sosial pada anak terlantar lebih ditingkatkan 


\section{Diklus: Jurnal Pendidikan Luar Sekolah, 1(2), September 2017 - 217 Hanif Taufiqul Hakim}

lagi, agar kegiatan bimbingan kedepannya lebih baik dan tujuan dari program bimbingan benar-benar tercapai secara maksimal.

b. Peran pendamping sangat diperlukan dalam kegiatan bimbingan anak sehingga perlu dipertahankan yaitu sebagai pendidik (educator) penghubung (mediator) pemampu (enabler) perantara (broker) fasilitator (fasilitator). Selain ke lima peran pendamping juga perlu ditambah maupun diperluas sehingga tujuan pendampingan pada anak dapat tercapai secara optimal.

c. Untuk menanggapi faktor penghambat dalam pelaksanaan bimbingan diperlukan upaya yang maksimal dan kreatif dari pihak sasana/pendamping/pembimbing untuk memanfaatkan faktor pendukung bimbingan.

\section{DAFTAR PUSTAKA}

Abdullah, Hanafi dan Mulyadi Guntur Waseso. 1984. Penelitian untuk mengevaluasi Efektifitas Program Kemasyarakatan. Surabaya: Usaha Nasional.

Anwar. 2006. Pendidikan Kecakapan Hidup(Life Skill) Education. Bandung: Alfabeta.

Anonim. Badan Pusat Statistik. Arikunto, Suharsimi \& Cepi Safruddin. 2014. Evaluasi Program Pendidikan.

Jakarta: Bumi Aksara.

Chulaifah. 2015. Pemberdayaan pada penyandang masalah kesejahteraan kesejahteraan sosial. Yogyakarta: B2PK3KS Press.

Departemen Sosial RI. 1995. Pedoman Penyelenggaraan Pembinaaan Kesejahteraan Sosial Anak Melalui Panti Sosial Asuhan Anak. Jakarta: Departemen Sosial RI. . 2006. Pedoman Pelaksanaan Pelayanan Dan Resos Anak Yang Berkonflik Dengan Hukum Di Panti Sosial. Jakarta: Departemen Sosial RI.

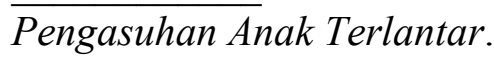

Yogyakarta: B2P3KS Press.

2008. Pedoman Pelayanan Anak Terlantar Berbasiskan Keluarga dan Masyarakat. Jakarta: Depsos RI.

Ditjen Diklusepa., Depdiknas. 2013. Pedoman Penyelenggaraan Program Kecakapan Hidupi(Life Skills) Pendidikan Non Formal. Jakarta: Ditjen Diklusepa.

Djuanda, Deden. 2007. Anak dan Masalah Keterlantaran Potret Penanganan dan Pengembangan Sisten Panti Asuhan. Bandung: BBPPKS

Enni Hardati,dkk. 2010. Sebuah Kepedulian Terhadap Anak Terlantar(studi kasus) Pengasuhan Anak Terlantar Di Provinsi Nusa Tenggara Timur. Yogyakarta: B2P3KS Press.

Hamalik, Oemar. 2003. Proses Belajar Mengajar. Jakarta: PT Bumi Aksara 
Diklus: Jurnal Pendidikan Luar Sekolah, 1(2), September 2017 - 218 Hanif Taufiqul Hakim 